\title{
DO ATRASO CULTURAL À DECADÊNCIA DOS ESTUDOS: UM TÓPICO ANTIQUÍSSIMO NAS POLÉMICAS PEDAGÓGICAS
}

\section{CULTURAL DELAY AND DECADENCE OF STUDIES: AN OLD TOPIC IN THE PEDAGOGICAL CONTROVERSIES}

\begin{abstract}
Resumo: No De oratore (1.2.7-1.6.20) Cícero aponta as razões da escassez de oradores excelentes. Mudadas as circunstâncias, no Dialogus de oratoribus (1.1), Tácito procura as causas da decadência da oratória. Mas foi talvez Quintiliano quem estabeleceu as bases de uma nova argumentação: no De causis corruptae eloquentiae justificava-se a elaboração de uma obra crítica menos pelo estado incipiente das artes do que pelo estado decadente dos estudos. A partir do Renascimento a syncrisis torna-se ainda mais complexa. As querelas dos antigos e dos modernos, ou dos oradores e dos causídicos, são amplificadas por velhos tópicos, como o taceat superata uetustas ou a analogia entre a translatio imperii e a translatio studii. Neste quadro convirá compreender a recepção do diálogo de Tácito na passagem do séc. XVI para ao séc. XVII, tempo em que as instituições escolares parecem reganhar certa estabilidade. $\mathrm{O}$ rastreio de temas e motivos taciteanos, presentes na cultura portuguesa, conclui-se com as críticas severas que ao 'seiscentismo', reino cadaveroso, reino da estupidez, dirigiram as 'luzes' do séc. XVIII (José Agostinho de Macedo) e do séc. XX (António Sérgio).
\end{abstract}

Belmiro Fernandes Pereira

Palavras-chave: Retórica, oratória, progresso pedagógico, decadência, reforma dos estudos, renascimento, luzes.

\begin{abstract}
In his De oratore (1.2.7-1.6.20) Cicero points out some reasons why excellent orators are so rare. Under different circumstances, in his Dialogus de oratoribus (1.1) Tacitus states the reasons for the decadence of oratory. But it may well have been Quintilian, who set the ground for a new form of argumentation: in his De causis corruptae eloquentiae he argued for a critical work based on the decadence, rather than the incipience of rhetorical studies. From Renaissance onwards such syncrisis will get still more complex with the antiquil moderni and the oratores/causidici quarrels, boosted by old topoi like taceat superata uetustas or the translatio imperiiltranslatio studii analogy. Such framework is key to understanding the reception of Tacitus' dialogue in the late XVI century and the early XVII century, a time in which educational institutions appear to have regained some stability. The screening of Tacitus' themes and motifs ends with the harsh criticism aimed by the 'enlightened' José Agostinho de Macedo and António Sérgio at the 17th century trends ('Seiscentismo'), 'cadaverous realm', 'reign of stupidity'.
\end{abstract}

Keywords: Rhetoric, oratory, pedagogical progress, decadence, education reform, Renaissance, Enlightenment.

1 É professor na Faculdade de Letras da Universidade do Porto junto ao Departamento de Estudos Portugueses e Românicos. Doutor em Estudos Clássicos pela Universidade Coimbra. Suas áreas de pesquisa concentram-se em retórica, literatura latina e humanismo renascentista. É investigador associado do Centro de Estudos Clássicos e Humanísticos da Universidade de Coimbra e Presidente da Sociedade Portuguesa de Retórica. , no Departamento de Estudos Portugueses e Românicos. CECH-UC 
excelentes, pelos seus méritos ou pela sua fama, e porque na nossa época tudo parece tão árido e desprovido de eloquência que já nem a palavra orador se conserva. É verdade, agora usamosesse termo apenas para designar osantigos, pois os bem-falantes preferemser conhecidos comocausídicos, advogados, patronos ou qualquer outra coisa, em vez de oradores2 (Dial., 1.1)

Com este lugar-comum abre o Dialogus de oratoribus. Se Cícero elaborava o De oratore por causa do estado incipiente dos estudos retóricos, aqui são as causas da decadência da arte oratória que justificam a composição. Assim se apresenta o texto de Tácito,desde o proémio, como reverso do diálogo ciceroniano. No De oratore os romanos superam os gregos na arte de governar e na arte militar, mas são-lhes inferiores na arte oratória. O diálogo constituiria uma tentativa de compreensão das causas desse atraso; partindo da ideia consensual da utilidade da retórica, Cícero julga encontrar na vastidão de conhecimentos exigidos ao orador perfeito a causa daescassez de oradores excelentes. O Dialogus de oratoribus inverte o pressuposto: todos os intervenientes, à excepção de Apro, consideram que a oratória entrou em declínio e que já pouco tem a ver com a grande eloquência do fim da época republicana.

Por conseguinte, é a pergunta inicial atribuída a Fábio Justo que fixa o rumo do debate evocado por Tácito em moldes ciceronianos. O próprio Cícero não estranharia tal adaptação, pois nas Tusculanae tinha observado:é um facto que a glória da eloquência passou de um nível humilde à máxima perfeição, de tal modo que, segundo o que parece ser uma lei geral da natureza, está a envelhecer e parece em breve tempo ir reduzir-se a nada3.

Outras causas para o declínio da oratória procura o historiador romano, através de uma argumentação política que recusa qualquer optimismo pedagógico. A ideia da decadência da arte retórica tornava-se corrente. Séneca, o Velho, tinha apontadocomo causas desse declínio a corrupção dos costumes, o desfavor público, a impossibilidade de emular a alta oratória republicana. Mais vozes se lhe juntaram, Petrónio, Plínio, Dionísio Longino, Juvenal. Mas quem reagiu seriamente contra a retórica reduzida a exercícios de escola ou a entretenimento da alta sociedade foi Quintiliano.

No De causis corruptae eloquentiae, intertexto do Dialogus de oratoribus, o calagurritano acusa Demétrio de Faléron e Cássio Severo de terem popularizado as declamationes. No livro II da Institutio oratoria(2.11-12), antes da tractatio das partes canónicas da arte, Quintiliano refuta as previsíveis objecções dos que negligenciavam a preparação técnica.

2Dialogus, 1.1 Saepe ex me requiris, Iuste Fabi, cur, cum priora saecula tot eminentium oratorum ingeniis gloriaque floruerint, nostra potissimum aetas deserta et laude eloquentiae orbata uix nomen ipsum oratoris retineat; neque enim ita appellamus nisi antiquos, horum autem temporum diserti causidici et aduocati et patroni et quiduis potius quam oratores uocantur.

3Cícero, Diálogos em Túsculo, introd., trad. e notas de J. A. Segurado e Campos, lisboa, Gulbenkian, 2014 , p. 98. 
Dirige a occupatio contra os declamadores que se diziam capazes de discursar de improviso, com impetu, substituindo o cuidado com a dispositio por grandes sententiae desconexas. Nos oradores «que se fingem incultos para parecerem mais vigorosos»; na sua amoralidade,que faz o maledicente passar por homem livre, o atrevido por valente, o tagarela por copioso; na actio teatral dos que levantam a voz, aplaudem, pateiam, batem nas coxas, no peito, na testa, arquejam, correm de um lado para outro, bufam, agitam a cabeça como loucos; neste retrato caricatural deixa de buxada a oratória dos declamadores. Quintiliano felicita-os, ironicamente, por terem alcançado a facúndia sem trabalho, sem método, sem disciplina4.A crítica aos abusos dos pregadores,que Erasmo propagará no séc. XVI, talvez encontre aqui alguma da sua tópica.

Havia outro tipo de declamatio, as questões infinitas, que, por serem muito úteis, Cícero recomendava (Brutus, 309-310)5. Mas, com a alteração das condições políticas, não só essa doutrina tinha perdido pertinência como o género deliberativo quase desaparecera. Por isso até a reacção classicizante de Quintiliano tinha limites. Se em Cícero ainda ecoa a concepção aristotélica da retórica, dicere adposite ad persuadendum, na Institutio Oratoriaa retórica transforma-se em arte literária. Mais do que arte da persuasão, disciplina subsidiária da política e da filosofia, a retórica para Quintiliano torna-se bene dicendi scientia (IO 2.15.38), a arte que convém ao bonus uir6. A retórica quintilianista distingue-se, portanto, por um sincretismo que a torna anacrónica. Quintiliano dedica o livro XII da Institutio à formação do orador, mas ao fazêlo revela mais os seus desejos do que sentido de oportunidade. A oratória degradara-se a ponto de os seus únicos representantes serem agora Éprio Marcelo e Víbio Crispo, dois delatores. Esta classe de homens sem escrúpulos suscitava ódio tão fundo quea perseguição implacável que lhes moverá Trajano há-de motivar grande parte do Panegírico de Plínio. Domício Afro, mestre de Quintiliano, foi um dos primeiros delatores; nos tempos de Nero e de Domiciano, maisfamoso pela sua impiedadeficou Aquílio Régulo, meio-irmão de Messala, uma das personagens principais do diálogo de Tácito ${ }^{7}$.

Quintiliano escreveuo De causis corruptae eloquentiae por volta do ano 89, a Institutio Oratoria em 95; Tácito terá redigido o Dialogus entre 100-109. Significa esta cronologia que as considerações feitas no Dialogus não podem deixar de se aplicar também à reforma tentada por

4Vd. C. O. Brink, «Quintilian's De Causis Corruptae Eloquentiae and Tacitus' Dialogus de Oratoribus», The Classical Quarterly 39 (1989), pp. 472-503.

5Vd. M. Winterbottom, «Declamation», Oxford Classical Dictionary, $3^{a}$ ed., 1996, pp. 436-437; Manfred Kraus, «Exercitatio», Historisches Wörterbuch der Rhetorik, v. 3, ed. G. Ueding, Berlin, De Gruyter, 1996, pp. 71-123. 6 «Sit ergo nobis orator quem constituimus is qui a M. Catone finitur, uir bonus dicendi peritus, uerum, id quod et ille posuit prius et ipsa natura potius ac maius est, utique uir bonus» $(I O, 12.1 .1)$.

7Vd. Steven H. Rutledge, «Delatores and the Tradition of Violence in Roman Oratory», American Journal of Philology 120 (1999), pp. 555-573, e G. Calboli, «Tra corte e scuola: la retorica imperiale a Roma», Vichiana 1, $3^{\mathrm{a}}$ ser., 1-2 (1990), pp. 17-39. 
Quintiliano. O debate inicia-se com Apro a defender as vantagens da oratória (5.3-10), enquanto Materno advoga a causa da poesia (11-14). Depois surge Messala, que lança a querela dos Antigos e dos Modernos, comparandoa oratória contemporânea coma eloquência antiga. Para Apro os modernos nada têm a invejar (16.4-23); Messala defende o contrário (25-26). Estabelecidos os termos do debate, Apro retira-se e o diálogo desenvolve-se entre Materno e Messala. Ambos concordam que a oratória está em declínio. Messala sustenta que a degradação tem origem nas mudanças pedagógicas. Para Materno a causa da corrupção da eloquência é mais política que ética, pois resulta de constrangimentos no uso da palavra.

O Dialogus apresenta uma estrutura complexa. Poderia Materno indicar as razões que o levaram a trocar a oratória pela poesia, mas Tácito adia a resposta. Depois de uma digressão, mais aparente que real, sobre a preeminênciada poesia ou da oratória, Apro toma a defesa dos modernos e quase transforma o debate numa causa judicial. Messala só agora entra em cena; a sua ausência permitiu o ataque ao seu meio-irmão Régulo. Como aristocrata de velha cepa, Messala sustenta a posição antimoderna. Para evitar debate tão estéril, Materno intervém e pedelhe que deixe de se apresentar como laudator temporis acti:

Estais a ver a força, o ardor oratório, do nosso amigo Apro? Com que caudalosa eloquência, com que fúria defendeu os modernos? Com que cópia de palavras e variedade de argumentos atacou os antigos? (...) Vamos, Messala, não deixes de cumprir o que prometeste. Não precisamos de defensores dos antigos (...) Apresenta-nos antes as razões porque tanto nos afastámos da sua eloquência8.

A resposta explícita e cabal Messala só a dará mais tarde (Dial. 32.5-7), quando reclamar, à maneira ciceroniana, que o orador perfeito estude a fundo filosofia e direito. Por agora as causas da decadência da oratória mantêm-se no planoestritamente moral(Dial. 28.1-2, 4, 6 - 29.1-3):

Por certo ninguém ignorará que a eloquência e as demais artes perderam o antigo brilho, não tanto por falta de cultores, mas por indiferença dos jovens, negligência dos pais, ignorância dos mestres, por esquecimento dos costumes antigos. ${ }^{9}$

A vénia ao mos maiorum, natural num patrício, segue na pegada de Quintiliano. Quando

8 24. Quae cum Aper dixisset, «adgnoscitisne» inquit Maternus «uim et ardorem Apri nostri? Quo torrente, quo impetu saeculum nostrum defendit! Quam copiose ac uarie uexauit antiquos! (...) Tuum tamen, Messalla, promissum immutasse non debet. Neque enim defensorem antiquorum exigimus, (...) exprome nobis (...) causas cur in tantum ab eloquentia eorum recesserimus».

928. Et Messalla «(...) Quis enim ignorat et eloquentiam et ceteras artis desciuisse ab illa uetere gloria non inopia hominum, sed desidia iuuentutis et neglegentia parentum et inscientia praecipientium et obliuione moris antiqui? 
a república florescia, as crianças eram educadas pelas mães, por familiares, por aias criteriosamente escolhidas, não por amas alugadas. Assim governaram suas casas Cornélia, Aurélia ou, acrescenta Messala, Átia, a mãe de Augusto. Agoraum menino mal nasce vai parar às mãos de uma criadita grega ou de um escravo grego, que logo tratam de imbuí-lo, desde tenra idade, de patranhas e enganos. Obviamente, há aqui elementos tópicos, quae omnes sentimus, que ultrapassam a mera identificação de Messala com Quintiliano.

Quando responde directamente à questão, Messala aponta a ignorância do direito e o desinteresse pela filosofiacomo primam et praecipuam causamdo afastamento da eloquência antiga. Materno não se dá por satisfeito e pergunta que exercitationes produziam então tão bons oradores. Messala desvia-se para corroborarQuintiliano: a instrução retórica tornou-se meramente escolar, as declamationes são res fictae, os jovens perderam o contacto com a oratória viva do foro e dos tribunais (Dial., 33. 4 - 34).

No entanto, e em última instância, a resposta à pergunta inicial não pode ser de ordem pedagógica. Depois da controvertida lacuna do cap. 36, oanfitriãovolta ao debate para no epílogodar a explicaçãodevida desde o início: a razão da decadência da arte oratória é política. Na qualidade de primeiro professor pago pelo erário público, que até teve direito a aposentação, Quintiliano de certo modo estava comprometido. A corrupta eloquentia que execra pertence à schola, àsua escola-instituição, talvez a mais importantemanifestação de cultura produzida pelo novo regime. Mas airrelevância pública da oratória seria bem evidente. Suetónio, na vida de Augusto (Aug.26), para frisarcomo nas Filípicas a oratória ciceroniana se revelou impotente, recorda a brutal eloquência de Cornélio, o centurião que impôs Octávio aos senadores mostrandolhes o punho da espada: Hic faciet, si uos non feceritis. Ora, ao contrário de Quintiliano, Tácito fizera o seu cursus honorum e tinha, por isso, uma visão mais política. No Agrícolao historiador reconhece que o Senado se tornara irrelevante e que nas actuais condições só há lugar para o panegírico. NoDialogus, a pergunta de Fábio Justo tinha que ter resposta política e é já esse o sentido da discussão inicial sobre oratória e poesia. Materno abandona os tribunais para se dedicar à tragédia, por verificara inutilidade da participação na vida pública. Recusando o optimismo de Quintiliano, Maternoescuda-se nesta forma tácita de protesto. Por isso, em tom algo irónico e desenfadado, acaba Maternopor se juntar a Apro quanto à desnecessidade de um de causis corruptae eloquentiae. Ambos concordam quanto à sua inutilidade, ainda que por diferentes razões (Dial. 41).

A grande eloquência precisa do debate livre, da agitação do vento; como o fogo, nota Materno, a eloquência alimenta-seda lenha e brilha e ilumina enquanto arde.A posição de Materno, portanto, não é a de umlaudator temporis acti. Temuma visão mais moderada que a de 
Messala, mas mais realista que a de Quintiliano. O diagnóstico de Messala acaba por se tornar objecto de irrisão: para Materno a alta oratória da época republicananasce dos crimes, de concussão, de fraude, nasce das sedições, de assassinatos e exacções. Amagna eloquentiaafinal dependeria mais da licentia do que da libertas pois é o conflito, a perturbatio, que a gera.Ao contrário, foram a acalmia na vida pública, quies, o bem estar do povo, otium, a segurança do senado, tranquillitas, a autoridade do príncipe, disciplina, que tornaram pacata e inerme a arte oratória, foram essas vantagens que, por assim dizer, amansaram a eloquência.

Conclui Materno o seu discurso com sentenças que haviam de cair no gosto dos imitadores de Tácito do último quartel do séc. XVI e de numerosos tacitistas do século seguinte: 'o orador vive das aclamações, do aplauso, como sucede no teatro', 'a tão festejada alta eloquência nasce da libertinagem, a que os insensatos chamam liberdade'10. Com a máscara de autor de tragédias, sob a persona de Materno, evolui Tácito, pressentido-se nas suas sententiae oblíquas o historiador experimentado na simulação e na dissimulação. Se o teatro se tinha retirado para as recitationes, nem por isso perdera eficácia; também a eloquência, que era da mesma natureza, havia de encontrar formas de vencer as barreiras que a cerceavam.

Não se estranhará, portanto, que durante o Renascimento se mantenha o Dialogus sob reserva, até que por fim as circunstâncias resultantes da centralização do poder venham reclamar o seu contributo para a reorganização da República das letras. Tácito não só era conhecido no Quattrocento como, depois de rocambolescas buscas de manuscritos, acabou entre os primeiros autores clássicos a sair em letra de forma. De 1470 é a chamada editio Spirensis e a esta primeira edição seguiram-se outras vinte até Lípsio dar a lume o seu primeiro Tácito em 1574. No entanto, razões literárias, religiosas e políticas conjuraram-se para impedir que o autor latino tivesse grande fortuna ${ }^{11}$.

Em tempos de profundas reformas escolares, o tópico da decadência dos estudos conferia actualidade ao Dialogus de oratoribus. Assim sucede nas obras de Erasmo, García Matamoros e, precipuamente,em textos deLuís Vives. Bastará recordar que olivro IV do seu De causis corruptarum artium se intitula, precisamente, De corrupta rhetorica12. Não obstante, até ao último terço do séc. XVI, Tácito foi, em geral, um autor proscrito. Um estilo tão afastado do modelo tuliano, uma visão da história e da condição humana incompatível com a perspectiva cristã, certa acomodação ao despotismo imperial - apesar dos 'frémitos' de liberdade que alguns

\footnotetext{
${ }^{10}$ Oratori autem clamore plausuque opus est et uelut quodam theatro, magna illa et notabilis eloquentia alumna licentiae, quam stulti libertatem uocant.

${ }^{11}$ Sobre a recuperação do Dialogus vd. Belmiro Fernandes Pereira, Retórica e eloquência em Portugal durante a época do Renascimento, Lisboa, INCM, 2012, pp. 844-870.

${ }^{12}$ Cf.De disciplinis Libri XX, Antuérpia, Michael Hillenius, 1531.
} 
pressentem nos Annales e nas Historiae, condenaram o historiador latino a ficar à porta das classes. A reabilitação de Tácito sucede só com a edição dos Opera feita por Lípsio em 1574. Nos comentários que então compôs procurou o humanista flamengo mostrar a pertinência da história tacitiana, entendida uelut theatrum hodiernae uitae. A comparação de Tácito com o tempo presente torna-sefrequente. Agora, observam Lípsio, Muret ou Montaigne, apenas um tipo de orador se afigura possível, o conselheiro régio, e só um género oratório se mostra adequado, o discurso epidíctico; recomenda-se a substituição da eloquentia do orador pela prudentia do historiador. Um dos mais conspícuos seguidores de Justo Lípsio, Carlo Pasquali (1547-1627), no De optimo genere elocutionis tractatus (1596), defende que Roma atingiu a maturidade política e literária não na República, mas no Império, não na copia ciceroniana, mas na breuitas tacitiana. Se há paralelismo entre o regime imperial saído das guerras civis e as modernas monarquias absolutas, num e noutro caso o próprio movimento da História demonstraria a insuficiência do estilo ciceroniano. A proliferação de ofícios a secretis (secretarius, consiliarius, aulicus, legatus) impõe uma nova arte; mais do que saber falar convém saber calar, ganhando os discretos e a discrição novo sentido. Por tudo isto Tácito passará a ser lido e recomendado. Na Bibliotheca Selecta, cânone razoado dos melhores autores, publicado em Roma em 1593 para uso dos colégios e noviciados da Companhia, António Possevino para a puerilis et prima imitatiorecomendaCícero como autor único;para a iuuenilis imitatio admite a leitura de Quintiliano, Quinto Cúrcio, Veleio Patérculo, Lívio e César, porque «a Cicerone minimum abeunt»; mas para a adulta imitatio advoga todo o tipo de autores, sobretudo Salústio, Séneca e Tácito.

Educado pelos jesuítas no Colégio de Santo Antão, foi D. Francisco Manuel de Melo (1608-1666) uma das figuras mais representativas da cultura portuguesa do séc. XVII, já pelo percurso acidentado da sua vida pessoal e política, já por uma obra polimórfica e vastíssima. Constitui um caso singular deimitação adulta dos clássicos, no que se refere à recepção de Tácito,como no acolhimento do tacitismomoldado por humanistas como Muret e Lípsio ${ }^{13}$.

Tácito Português, biografia que ficou inédita, sugere até onde poderá ter ido a identificação do autor com o historiador latino. Apesar de texto inacabado, D. Francisco assumeo claramente como seu, quer noHospitaldas Letras (c. 1654), quer no rol definido nasObras Morales (1664). Aplicando a narrativa tacitianaàconcepção seiscentista do mundo como espaço cénico, Tácito português ao accionar a predilecção barroca pelo tropo da antonomásia não só intitula como condiciona a leitura da Vida e feitos de D. João IV. Mas sugere ainda que se veja 
em D. Francisco um Tácito redivivo, até pela correspondência que estabelece com textos coevos que jazem entre os pacientes do Hospital das Letras: o Tácito Español, de Baltasar Álamos de Barrientos, e Le Tacite François, do jesuíta René de Ceriziers.Junto deD. Teodósio II, uma espécie de vida paralela, Tácito Português torna-se exercício retórico in utramque partem, mas reitera também que a sua chave interpretativa se encontra na similitudo temporum. Transposições temporais, analogias, enlaçamo antigo e o moderno, mecanismo conhecido de Lípsio e de Álamos de Barrientos: «Otros son los hombres, o los nombres, pero no las costumbres». As virtualidades de Tácito, a sua maquiavélica energia, reclamam leitores discretos, capazes de aproximações contrastantes, senão contraditórias. De certo modo reproduz-se no Hospital das Letrasa pluralidade de vozes do Dialogus de Oratoribus em relação a Quintiliano. No quarto dos Apólogos Dialogais, a demorada e miúda discussão travada no contracenar das personagens leva a que Bocalino invective Tácito como «chapado velhacão, lisonjeiro e adulador como mil que andam por esses paços» ou a que a personagem Lípsio o louve como «gigante»e «patriarca dos estadistas».

À conta deentretenimento de quatro amigos, Lípsio, Bocalino, Quevedo e D. Francisco, «escritores de repreensões e emendas de vícios e costumes da República», oferece-se aqui um texto fundamental de teoria e de crítica literária. Tratando das causas da decadência da poesia, apreciam-se «os estilos dos poetas antigos e modernos» e os autores «que devem ser curados e os que não têm cura». Comoo Aprotacitiano, Lípsio ataca a poesia, coisa de«mancebos, damas e ociosos»; comAprosustenta que os modernos levam vantagem: se os antigos ressuscitassem «a gente fugiria deles»; Lípsio autor e Lípsio personagem consideram a poesia dom divino, veículo de subtis ideias e agudos conceitos, elemento imprescindível ao ideal do discreto; por seu turno Quevedo lembra que «os antigos também foram modernos e nós também havemos de ser alguma hora antigos».Ficam estas associações no entanto algo comprometidas pelo catálogo incompleto que das obras de Tácito dá Bocalino: «Só sabemos de três obras suas: a História de Roma, imperfeita, os Anais de alguns emperadores e a vida de seu sogro Júlio Agrícola, tudo por acabar, porque o Tácito, assim como era malcontente dos outros, também de si não era satisfeito».

Se Materno no Dialogus aparece sempre insatisfeito com as suas tragédiasMedeia e Tiestes, também no apólogo de D. Franciscose desenha uma concepção aristocrática de poesia. No entanto, a reaproximação da retórica à poética, promovida pela estética barroca, mais se manifestará nos dois volumes da Nova Arte de Conceitos de Francisco Leitão Ferreira, publicados em 1718 e 1721: 
«Tomarei por assunto das minhas exposições, nestas esclarecidas e nocturnas conferências, o meditar e dictar um método ou arte de fabricar conceitos por imagens e ideias engenhosas, que terá uma nova Dialéctica da Poesia, uma Teoria Lógica da Eloquência e uma útil Retórica da Retórica» (NAC 1.2).

A Nova Arte de Conceitos de Francisco Leitão Ferreira (1667-1735), concebida como série de lições ministradas durante seis anos na Academia dos Anónimos, foi a primeira obra de teoria explícita em língua portuguesa a ter impacto na produção retórica e poética. Partindo do cânone de tratadistas greco-latinos, enriquecido com textos divulgados na segunda metade do séc. XVI (Demétrio de Faléron, Longino, a Poética e a Retórica aristotélicas), Leitão Ferreira tanto faz bom uso de poetas quinhentistas (Camões, Petrarca, Garcilaso, Boscán, Ronsard) e de autores marcantes do barroco europeu, como demonstra sólida formação humanística e profundo conhecimento das doutrinas literárias de Seiscentos.Propondo-se «reduzir a arte as operações livres do entendimento», Leitão Ferreira submete os conceitos engenhosos ao iudicium retórico, à imagem dos conceitos formais submetidos ao iudicium da dialéctica. $\mathrm{O}$ facto de o delectus rerum depender do iudicium levara muitos, desde Agrícola, a acrescentar uma sexta parte à arte retórica. Sem chegar a tanto, Leitão Ferreira, ao submeter os conceitos produzidos pela natureza ao juízo do entendimento, por um lado activa conspícuas correntes do humanismo europeu, por outro realiza a 'redução tropológica' operada pela estética barroca. É esse o intento da Nova Arte de Conceitos, mostrar que a raiz de todos os conceitos engenhosos «he sem duvida alguma a Metafora», não só porque enriquece abundantissimamente o entendimento humano, mas porque oferece ao mesmo entendimento «huma exactissima, \& finissima pedra de toque, com que conhece, \& separa o vil, do precioso».Essa nova arte que propõe para a elaboração de conceitos engenhosos não está isenta de intenção reformadora e de reflexões sobre a decadência da oratória, alegando já como remédio o exemplo do Padre António Vieira.O mesmo propósito regenerador, animado por um propósito beletrístico que acentua a redução da retórica a uma teoria de tropos e figuras,manifestar-se-áainda no Espelho da eloquência portuguesa illustrado pelas exemplares luzes do verdadeiro sol da elegância, o Venerável padre António Vieira, editado em Lisboa, em 1734. O remédio, porém, chegava tarde.

O tópico tacitiano da decadência da oratória integra-se por meados do séc. XVIII no tema mais geral da corrupção dos estudos, quando as luzes do despotismo estrangeirado se transformam em violentoataque ao suposto anquilosamento do ensino ministrado nos colégios da Companhia. A crítica sistemática programada por Pombalfoi servida em quatro textos capitais, noCompêndio Histórico da Universidade de Coimbra, na Dedução cronológica e analítica, nos Estatutos [pombalinos] da Universidade de Coimbra, no Verdadeiro Método de Estudar (1746), 
de Luís António Verney ${ }^{14}$.

Nas cartas quinta e sexta do Verdadeiro Método de Estudar trata Verney da reforma do ensino da retórica, arte fundamental nas escolas baixas:

(...) por pouco que se examine o que é Retórica, achar-se-á que é Arte de persuadir, e, por consequência, que é a única coisa que se acha e serve no comércio humano e a mais necessária para ele (...) todo o lugar é teatro para a Retórica. (...) Não há coisa mais útil que a Retórica, mas não há alguma quecom mais negligência se trate neste Reino. Se Vossa Paternidade observar o que os Mestres ensinam nas escolas, achará que é uma embrulhada que nenhum homem, quanto mais rapaz, pode entender. Primeiramente, ensinam a Retórica em Latim. Erro considerável, porque nada tem a Retórica com o Latim, sendo que os seus preceitos compreendem e se exercitam em todas as línguas».«(...) Digo, pois, que o primeiro emais importante ponto que deve advertir quem quer formar o bom gosto literário é fugirtotalmente destas Retóricas comuns, não só manuscritas, mas também impressas. Estoupersuadido que elas são a primeira ruína dos estudos, porque inspiram mui mausprincípios e não ensinam o que devem. «(...) Isto suposto, é necessário desterrar uma e admitir outra sorte de Retórica. Já assentámos que a Retórica deve ser em português para os que nasceram em Portugal; porque assim se entendem os preceitos, e na sua mesma língua se mostram osexemplos. Não havemos de carregar os rapazes com dois pesos: entender a língua e entender a Retórica».

As severas críticas ao 'seiscentismo' não desapareceram com a morte de D. José e o afastamento do seu valido. Até o desconcertante José Agostinho de Macedo (1761-1831), no poema satírico Os burros ou o reinado da sandice (Paris, Off. Rignoux, 1827), carrega de novo contra o reino cadaveroso, reino da estupidez, o triste seiscentismo, o escuro seiscentismo. Em 1852 sai em Lisboa, da Typographia de Sylva, a primeira e, tanto quanto julgo saber,a únicatradução em língua portuguesa do Dialogus de oratoribus. José Maria de Almeida Araújo Correia de Lacerda, deão da Sé Patriarcal e Deputado às Cortes, tradutor e lexicógrafo, deixou aí uma meritória versão,feita sobre o texto de Lipsius e enriquecida com noventa notas históricoliterárias.

14Que a propaganda pombalina, mantida cegamente por corrrentes de vária extracção, não resiste ao estudo e à crítica tem-no vindo a demonstrar a investigação mais recente sobre história da ciência. A este respeito vd. Henrique Leitão, A Ciência na Aula da Esfera do Colégio de Santo Antão, 1590-1759, Lisboa, 2008; Henrique Leitão, «Azulejos que testemunham uma tradição de ensino científico», Azulejos que ensinam, Coimbra, Museu Nacional Machado de Castro, Centro de Matemática da Universidade de Coimbra, 2007, pp. 16-33;John O'Malley et al. (eds.), The Jesuits II: Cultures, Sciences, and the Arts, 1540-1773, Toronto, University of Toronto Press, 2006; Magno de Mello - Henrique Leitão, «A pintura barroca e a cultura matemática dos Jesuítas: O Tractado de Prospectiva de Inácio Vieira, S. J. (1715)», Revista de História de Arte, 1 (2005) 95-142; Luís Saraiva - Henrique Leitão (eds.), The Practice of Mathematics in Portugal, Coimbra, Acta Universitatis Conimbrigensis, 2004;Mordechai Feingold (ed.), The New Science and Jesuit Science: Seventeenth Century Perspectives, Dordrecht, Kluwer Academic Publishers, 2003;Henrique Leitão, «Galileo's Telescopic Observations in Portugal», em: José Montesinos y Carlos Solís (eds.), Largo Campo di Filosofare. Eurosymposium Galileo 2001 (La Orotava: Fundación Canaria Orotava de la Historia de la Ciencia, 2001), pp. 903-913. 
Por muitas vias veio a perdurar, ao longo dos sécs. XIX e XX, o lugar-comum do declínio da arte oratória, da decadência dos estudos, do atraso cultural e económico do país, desde o panfleto sobre as Causas da Decadência dos Povos Peninsulares, em que Antero de Quental sumaria teses do historiador Alexandre Herculano, até aos ensaios «O Reino cadaveroso ou o problema da cultura em Portugal» e, sobretudo, «O seiscentismo» (1926) texto de polémica política publicado por António Sérgio na revista Seara Nova. O antijesuitismo moderado deste doutrinador e oposicionista do Estado Novoleva-o a declarar na controvérsia com o integralista António Sardinha: «admirar o Seiscentismo é querer manter-nos no grande eclipse da cultura nacional; é querer adorar o maior cancro de que ainda sofre o Português: a mentalidade anticientífica, anticrítica quenos faz... índios da Europa desde então. Portugal, no século XVI, foi dos pioneiros da investigação científica (...) o Seiscentismo, porém, fê-lo cair dessas alturas no charco lodoso da Retórica, em que inda jaz».

Que tenha sido por via de um diálogo latino sobre as causas da decadência da oratória que este tópico pedagógico persistiunão só parecerá irónico como sinal inequívoco da sua actualidade. 